\title{
LETTER FROM THE EDITOR.IN.CHIEF
}

The publication of the Special Issue to commemorate the tenth anniversary of JIBS has been delayed until the Spring of 1981. Because we have received a considerable number of review articles and other manuscripts to consider for the Special Issue, the refereeing and selection process for the anniversary issue of JIBS has been more complex and exacting than for the regular issues. Generally, three or even four reviewers have evaluated manuscripts for the anniversary issue. This process has been complicated further because a number of manuscripts were received somewhat late and because topics overlapped. Most articles have required substantial revisions before they could be published.

The Special Issue will feature state-of-the-knowledge articles on many subjects in International Business. Ideally, we would have liked to cover all major fields, but that will not be feasible - given the mix of manuscripts received and the evaluations of referees. We now expect that the first issue in 1981 will be the anniversary number and that a few review articles will be carried over as part of the second issue in 1981.

Looking back to 1975 when we assumed editorial responsibilities for JIBS, we find that the largest number of articles have been published in international management, international finance, and international marketing-roughly equally. These three fields also lead in manuscripts received, with international finance in first place followed by international marketing and international management. Other published articles have been scattered over many fields - international accounting, international trade, direct investments in the United States, direct investments in foreign countries, multinational enterprise, and technology transfer, to name a few. Of course, some problems exist in classifying certain articles neatly into one field; however, during 1980, we received by far the largest number of manuscripts on international finance.

I consider it important to maintain some balance among articles published to respond to the diverse interests of our readers. I want to encourage the submission of more manuscripts in emerging fields in which we have not published many articles in the past. Further, scholars in International Business should lead the way in innovative research rather than follow the business community; for example, most of the advances in international strategic planning during the last decade have been made by consultants and business analysts rather than academicians. Considerable opportunities exist for more imaginative even multidisciplinary research focusing on emerging international managerial issues. It is up to scholars to take up these challenges.

William A. Dymsza Editor-in-Chief 